\title{
Acetic acid treatment in S. cerevisiae creates significant energy deficiency and nutrient starvation that is dependent on the activity of the mitochondrial transcriptional complex Hap2-3-4-5
}

\section{Ana Kitanovic ${ }^{1+}$, Felix Bonowski ${ }^{1+}$, Florian Heigwer ${ }^{1+}$, Peter Ruoff ${ }^{2}$, Igor Kitanovic ${ }^{1}$, Christin Ungewiss ${ }^{1}$ and Stefan Wölfl ${ }^{1 *}$}

1 Institute for Pharmacy and Molecular Biotechnology, Heidelberg University, Heidelberg, Germany

${ }^{2}$ Faculty of Science and Technology, Centre for Organelle Research, University of Stavanger, Stavanger, Norway

Edited by:

Frank Madeo, KFU, Austria

Reviewed by:

William Burhans, Roswell Park

Cancer Institute, USA

Valter Longo, University of Southern

Califonria Los Angeles, USA

\section{${ }^{*}$ Correspondence:}

Stefan WölfI, Institute for Pharmacy

and Molecular Biotechnology,

Heidelberg University,

Heidelberg, Germany.

e-mail:wolf|@uni-hd.de

${ }^{t}$ These authors equally contributed to this work.
Metabolic pathways play an indispensable role in supplying cellular systems with energy and molecular building blocks for growth, maintenance and repair and are tightly linked with lifespan and systems stability of cells. For optimal growth and survival cells rapidly adopt to environmental changes. Accumulation of acetic acid in stationary phase budding yeast cultures is considered to be a primary mechanism of chronological aging and induction of apoptosis in yeast, which has prompted us to investigate the dependence of acetic acid toxicity on extracellular conditions in a systematic manner. Using an automated computer controlled assay system, we investigated and model the dynamic interconnection of biomass yield- and growth rate-dependence on extracellular glucose concentration, $\mathrm{pH}$ conditions and acetic acid concentration. Our results show that toxic concentrations of acetic acid inhibit glucose consumption and reduce ethanol production. In absence of carbohydrates uptake, cells initiate synthesis of storage carbohydrates, trehalose and glycogen, and upregulate gluconeogenesis. Accumulation of trehalose and glycogen, and induction of gluconeogenesis depends on mitochondrial activity, investigated by depletion of the Hap2-3-4-5 complex. Analyzing the activity of glycolytic enzymes, glyceraldehyde-3-phosphate dehydrogenase (GAPDH), pyruvate kinase (PYK), and glucose-6-phosphate dehydrogenase (G6PDH) we found that while high acetic acid concentration increased their activity, lower acetic acids concentrations significantly inhibited these enzymes. With this study we determined growth and functional adjustment of metabolism to acetic acid accumulation in a complex range of extracellular conditions. Our results show that substantial acidification of the intracellular environment, resulting from accumulation of dissociated acetic acid in the cytosol, is required for acetic acid toxicity, which creates a state of energy deficiency and nutrient starvation.

Keywords: growth dynamic, response surface modeling, automated assay, acetic acid, Hap4p, intracellular pH, metabolic control

\section{INTRODUCTION}

Basic metabolic pathways provide energy and molecular building blocks required for growth, maintenance and repair. Changes in the metabolome correlate with declining functions with age. Network analysis of metabolism can help to determine how failures in metabolic control, required to maintain stability and homeostasis within living systems, can lead to senescence and aging.

Acetic acid is a normal end product of alcoholic fermentation in S. cerevisiae that cannot be metabolized by glucose-repressed yeast cells. In undissociated form acetic acid is freely membrane permeable and enters the cell by simple diffusion. At higher extracellular $\mathrm{pH}$ acetic acid will dissociate to the acetate anion, a form that is relatively membrane-impairment. Acetic acid was also shown to induce apoptosis in yeast cells involving release of cytochrom $\mathrm{c}$ in a mitochondria dependent apoptotic pathway (Ludovico et al., 2002; Pereira et al., 2007). Almeida et al. (2009) presented that induction of apoptosis triggered by acetic acid is accompanied by severe amino acids starvation and activation of the TOR signaling pathway. Acetic acid was also identified as a cell-extrinsic mediator of cell death during chronological aging in S. cerevisiae (Burtner et al., 2009).

These observations suggest that the cellular response to acetic acid and the induction of apoptosis could strongly depend on specific combinations of extracellular conditions, like medium $\mathrm{pH}$ or glucose availability. To investigate how various combinations of extracellular factors and metabolic activity modulate the biological response of yeast cells to acetic acid treatment, 
we performed a large scale study using a computer-controlled robot-system together with a mathematical algorithm for experimental planning to appropriately cover the full space of multiple culture/medium parameters by automated variation of experimental conditions (Bonowski et al., 2010). Experiments on the robot systems are controlled by $\mathrm{R}$ scripts using object-oriented descriptions of experimental parameters. Thus, providing only a small set of defined stock solutions, yeast growth is automatically analyzed in a multidimensional parameter space. By covering the whole range of all possible combinations, we try to avoid a bias in experimental conditions that could influence the experimental results (Kovárová-Kovar and Egli, 1998; Narendranath and Power, 2005). The resulting datasets of growth kinetics depending on the variable parameters are visualized using multidimensional regression methods and response surface modeling that facilitate the determination of the optimum values for the factors under investigation. Using this automated procedure we provide a detailed model for the dynamic dependence of biomass yield and growth rate on extracellular glucose concentration, $\mathrm{pH}$ conditions and acetic acid concentration. Further investigation revealed that accumulation of acetic acid in the cytosol results in inhibition of the respiratory chain and ceased uptake of carbohydrates creating significant energy deficiency and nutrient starvation. Acetic acid also directly influenced the activity of key metabolic enzymes, glyceraldehyde-3-phosphate dehydrogenase (GAPDH), pyruvate kinase (PYK), and glucose-6-phosphate dehydrogenase (G6PDH).

\section{MATERIALS AND METHODS STRAINS AND CULTURING CONDITIONS}

The yeast strains used in this study are: FF 18984 (MATa leu23,112 ura3-52, lys2-1, his7-1) and $\Delta$ hap4 (MATa leu2-3,112 ura352, lys2-1, his7-1; hap4::KanMX4). Yeast cells were grown in rich (YPD) medium containing $10 \mathrm{~g} \mathrm{l}^{-1}$ Yeast Extract, $20 \mathrm{~g} \mathrm{l}^{-1}$ Bacto peptone, and different glucose concentrations (as indicated; 20, $10,5 \mathrm{~g}$, or $2.5 \mathrm{~g} \mathrm{l}^{-1}$ ). Cell were grown over night at $30^{\circ}$ with agitation, collected by centrifugation at $3500 \mathrm{rpm}$ for $5 \mathrm{~min}$, suspended in water and used as a cell stock for the assays.

\section{GROWTH DYNAMIC EXPERIMENTAL SETUP}

Experiments were carried out by a Tecan Genesis RSP 150 robot and a Tecan Ultra II plate reader. The system is controlled by a set of $\mathrm{R}$ packages developed in our lab that provide a general experimental framework for fluid mixture based experiments. The program packages enable automated variation of experimental conditions by generating tables of concentrations of each assay component. Pipetting volumes are calculated from these concentrations and all pipetting and measurement steps are executed automatically. The robot pipettes all components into 96 $\mathrm{U}$-shaped well plates and growth is automatically analyzed in a plate reader controlled by a modified version of the XFluor Excel macros. The protocols allow fully automated configuration, execution and export of measurement data without user-interactions [for more details see Bonowski et al. (2010)].

Medium stock solutions were defined as fixed components (4xYP-yeast extract/peptone/dextrose medium (YPD) and variable components (glucose, $\mathrm{pH}$, and acetic acid). The parameter space for the variable medium components was specified in terms of concentrations and $\mathrm{pH}$ values and a space-filling design was used to cover it with measurement points, 48 conditions for each strain. The $\mathrm{pH}$ was controlled by combination of two buffers adjusted to different $\mathrm{pH}$ values ( $50 \mathrm{mM}$ citrate/phosphate buffer). A spline fit method was applied to convert between buffer fractions and $\mathrm{pH}$ values. Medium components were pipetted first by multi-pipetting mode. Yeast cells in water were added to a final concentration of $0.2 \mathrm{OD}_{600}$ and growth kinetics were measured at $620 \mathrm{~nm}$ for 114 cycles at an interval of $10 \mathrm{~min}$. Reader thermostat was adjusted to $30^{\circ} \mathrm{C}$.

\section{QUANTITATIVE ASSESSMENT OF GLUCOSE, GLYCOGEN, AND TREHALOSE CONTENT}

In order to quantify glucose consumption and glycogen and trehalose accumulation, culture supernatant and cell pellet were collected at indicated time points. The procedure was performed as described previously (Parrou and Francois, 1997). Briefly, the cell pellet (collected from $20 \mathrm{OD}_{600}$ units of culture) was suspended in $250 \mu \mathrm{l} 0.25 \mathrm{M} \mathrm{Na}_{2} \mathrm{CO}_{3}$ and heated at $95^{\circ} \mathrm{C}$ for $4 \mathrm{~h}$ with occasional stirring. The suspension was adjusted to $\mathrm{pH} 5.2$ with $150 \mu \mathrm{l} 1 \mathrm{M}$ acetic acid and $600 \mu \mathrm{l} 0.2 \mathrm{M}$ sodium acetate buffer, $\mathrm{pH}$ 5.2. Half of this mixture was incubated overnight at $57^{\circ} \mathrm{C}$ with continuous shaking on a rotary shaker in the presence of $100 \mu \mathrm{g}$ of $\alpha$-amyloglucosidase from Aspergillus niger (Sigma). The second half of the mixture was incubated overnight at $37^{\circ} \mathrm{C}$ in the presence of $3 \mathrm{mU}$ trehalase (Sigma). The glucose released from glycogen and trehalose digestion as well the glucose content in the medium were determined with the glucose oxidase/peroxidase method (Cramp, 1967).

\section{MONITORING OF OXYGEN CONSUMPTION}

Oxygen consumption was monitored in OxoPlate ${ }^{\circledR}$ (PreSens; Germany) covered with a breathable membrane (Diversified Biotech, USA) in $150 \mu \mathrm{l}$ volumes containing the indicated medium conditions and $0.1 \mathrm{OD}_{600}$ units of cells. The plates were prepared using our computer-controlled automated experimental design. The signal of the oxygen fluorescence sensor and the optical density of the culture at $600 \mathrm{~nm}$ were measured continuously during indicated times with intervals of $10 \mathrm{~min}$. The calibration of the fluorescence reader was performed using a twopoint calibration curve with oxygen-free water $\left(80 \mathrm{mM} \mathrm{Na}_{2} \mathrm{SO}_{3}\right)$ and air-saturated water. Partial pressure of oxygen was calculated from the calibration curve.

\section{PREPARATION OF CELL-FREE EXTRACTS AND ENZYME ASSAYS}

All procedures were carried out at $0-4^{\circ} \mathrm{C}$. Crude extracts were prepared from $20 \mathrm{OD}_{600}$ units of cells with $1 \mathrm{~g}$ glass beads (0.4-0.5 mm diameter) in $0.5 \mathrm{ml} 20 \mathrm{mM}$ Hepes, $\mathrm{pH} 7.1,100 \mathrm{mM}$ $\mathrm{KCl}, 5 \mathrm{mM} \mathrm{MgCl} 2,1 \mathrm{mM}$ EDTA, and $1 \mathrm{mM}$ DTT. Samples were vortexed $(3 \times 5 \mathrm{~min}$ with cooling on ice in between $)$ in Mixer Mill MM 300 (Retsch). After centrifugation at $16,000 \mathrm{~g}$ for $15 \mathrm{~min}$ at $4^{\circ} \mathrm{C}$, the supernatants were immediately used for enzymatic assays. Protein content was determined by the method of Bradford (1976). All chemicals and enzymes for enzymatic assays were purchased from Sigma.

Glyceraldehyde-3-phosphate dehydrogenase (GAPDH; EC 1.2.1.12), pyruvate kinase (PYK; EC 2.7.1.40), and 
glucose-6-phosphate dehydrogenase (G6PDH; EC 1.1.1.49) activity were measured at $30^{\circ} \mathrm{C}$ by measuring NADH consumption or NADPH production, using a spectrophotometric assays as described earlier (Kitanovic et al., 2009).

Fructose 1,6 bisphosphatase (FBP1; EC 3.1.3.11) activity was measured at $30^{\circ} \mathrm{C}$ by coupling reactions of FBP1, phosphoglucoisomerase and G6PDH and measuring NADPH production, using a spectrophotometric assay. The reaction was made in $0.15 \mathrm{ml}$ containing $100 \mathrm{mM}$ Imidazole, $\mathrm{pH} 7.1,100 \mathrm{mM} \mathrm{KCl}$, $5 \mathrm{mM} \mathrm{MgSO}_{4}, 5 \mathrm{mM}$ EDTA, $0.7 \mathrm{mM} \mathrm{NADP}^{+}, 3.4 \mathrm{mM}$ glucose-6phosphate, and 10 units of phosphoglucoisomerase and G6PDH (EC 5.3.1.9 and EC 1.1.1.49, respectively). The reaction was initiated by the addition of crude extract and increase of absorbance at $340 \mathrm{~nm}$ was monitored.

Malate dehydrogenase (MDH; EC 1.1.1.37) activity was measured at $30^{\circ} \mathrm{C}$ by monitoring $\mathrm{NADH}$ consumption, using a spectrophotometric assay. The reaction was made in $0.15 \mathrm{ml}$ containing $50 \mathrm{mM}$ Tris/MES, pH 7.4, $200 \mathrm{mM} \mathrm{KCl}, 10 \mathrm{mM}$ $\mathrm{MgCl}_{2}, 0.625 \mathrm{mM} \mathrm{NADH}$, and $0.5 \mathrm{mM}$ oxaloacetate. The reaction was initiated by the addition of crude extract and decrease of absorbance at $340 \mathrm{~nm}$ was monitored.

Isocitrate dehydrogenase (IDH; EC 1.1.1.41) activity was measured at $30^{\circ} \mathrm{C}$ by monitoring $\mathrm{NADH}$ production, using a spectrophotometric assay. The reaction was made in $0.15 \mathrm{ml}$ containing $50 \mathrm{mM}$ Tris/MES, $\mathrm{pH} 7.5,100 \mathrm{mM} \mathrm{KCl}, 12 \mathrm{mM} \mathrm{MgCl}_{2}$, $0.625 \mathrm{mM} \mathrm{NADH}$, and $8 \mathrm{mM}$ isocitrate. The reaction was initiated by the addition of crude extract and decrease of absorbance at $340 \mathrm{~nm}$ was monitored.

\section{MONITORING OF INTRACELLULAR pH}

For cytosolic expression of ratiometric pHluorin we used pHluorin in an expression plasmid with a strong constitutive ADH1 promoter, kindly provided by Tobias Dick (Heidelberg) (Braun et al., 2010). For estimating the calibration curve, the cells were resuspended in a series of $50 \mathrm{mM}$ citrate-phosphate calibration buffers of defined $\mathrm{pH}, 5.0,5.5,6.0,6.5,7.0,7.5$, and 8.0 (supplements). Cells containing pHluorin reporter plasmid were grown in $260 \mu \mathrm{l}$ low fluorescence minimal F1 medium (Kitanovic and Wölfl, 2006) at $30^{\circ} \mathrm{C}$ in Tecan Ultra microplate reader (Tecan). Kinetic parameters were measured at 390/510 and $480 / 510 \mathrm{~nm} \mathrm{Ex} / \mathrm{Em}$. According to the calibration curve, we then calculated the internal $\mathrm{pH}$ values ( $\mathrm{pHin}$ ) from fluorescence ratios measured in the experimental part. Samples were measured in triplicates; the data shown represents one of three independent experiments.

\section{DATA ANALYSIS \\ Multivariate response surface modeling}

The large multidimensional datasets generated by our experimental framework require new approaches of explorative dataanalysis. To visualize the response of yeast to changes in medium composition, we use $2 \mathrm{D}$ slices of multivariate response surface models (RSMs).

Classical RSMs based on low order polynomials have a long and successful history as a tool for optimizing biotechnological processes (Popa et al., 2007; Fereidouni et al., 2009; Singh et al., 2009). The main advantages of these models are that they are mathematically simple, easy to optimize and provide a method to improve processes without having to carry out a large number of measurements. Unfortunately, fitting a fixed functional form to a dataset introduces a massive bias and is unlikely to yield an accurate description of a complex non-linear system (Jones, 2001), making them unsuitable as an explorative tool.

Non-parametric and semi-parametric regression techniques like Gaussian Random Process Regression (GRPR) can help to avoid these shortcomings (Cressie, 1993). The assumptions behind GRPR are much more general than those behind classical RSMs, giving them much more flexibility to fit the data in a less biased fashion. In this work, we show how the combination of automated experimenting and visualization of datasets using GRPR can help to get an intuitive understanding of the combined quantitative influence of multiple factors on the growth dynamic of yeast cultures.

Yeast growth in a liquid batch culture was expressed as exponential rate constant $\mu(\mathrm{t})$ where:

$$
\mathrm{dOD}(\mathrm{t}) / \mathrm{dt}=\mu(\mathrm{t}) \cdot \mathrm{OD}(\mathrm{t})
$$

In order to define growth kinetic over time a piecewise linear regression of $\log (\mathrm{OD})$ was determined:

$$
\begin{aligned}
\mathrm{OD}(\mathrm{t}) & =\mathrm{OD}\left(\mathrm{t}_{0}\right) \cdot \mathrm{e}^{\mu(\mathrm{t}) * \mathrm{t}} \\
& \Rightarrow \ln (\mathrm{OD}(\mathrm{t}))=\ln \left(\mathrm{OD}\left(\mathrm{t}_{0}\right)\right)+\mathrm{t} \cdot \mu(\mathrm{t})
\end{aligned}
$$

We developed an extension to the GRPR implemented in the fields $\mathrm{R}$ package for visualizing slices of multidimensional datasets and obtaining non-parametric surrogate models of experimental systems. The fields implementation uses generalized cross validation to obtain an estimation of the noise-level of the data and find optimal smoothing parameter (Marcotte, 1995). Our implementation also performs an optimization of the length-scale parameter of the covariance function in all dimensions of the model using the Nelder-Mead method as implemented in the $\mathrm{R}$ function optim with cross-validation error of fields as the objective function, and allows scaling of the axes with arbitrary functions that reflect $a$-priori assumptions about the sensitivity of the system to parameter changes in different regions of the parameter space. Certain axes are switched to logarithmic scaling, which is useful for many biochemical systems that show a large variability at low concentrations (Bonowski et al., 2010).

GRPR has been used extensively in the field of geostatistics, where it is commonly called Kriging (Cressie, 1993). A Gaussian process is a collection of random variables, any finite number of which have a joint Gaussian distribution (Rasmussen and Williams, 2006). In our setting, each observation at a point $x_{i}$ in the parameter space corresponds to one random variable of the Gaussian process. In GRPR, one assumes that the covariance of different observations is a function $k\left(x_{i}, x_{j}\right)$ of their locations in the parameter space. The joint distribution $f(X)$ of observations at a set $X$ of parameter combinations is given by

$$
f(X) \sim N\left(\mu, \sum=K(X)\right)
$$


where $N$ is a multivariate normal distribution and the entries $K_{i j}=k\left(x_{i}, x_{j}\right)$ of the covariance matrix are given by the covariance function.

Predictions $f\left(X^{*}\right)$ for unknown parameter combinations $X^{*}$ can be derived from the joint distribution with observations from measurements at locations $X$ as described in Cressie (1993). The choice of a covariance function $k\left(x_{i}, x_{j}\right)$ provides a way to influence on the properties of the resulting RSM.

Our models are based on a stationary covariance function of the "Gaussian" type that is one of the standard choices for a smooth covariance function (Cressie, 1993):

$$
k\left(x_{i}, x_{j}\right)=\sigma_{f}^{2} \exp \left(-\frac{1}{2 l^{2}}\left(x_{i}-x_{j}\right)^{2}\right)+\sigma_{n}^{2} \delta_{i j}
$$

In this formula, $\sigma_{f}$ describes the strength of correlation between measurements with similar parameters, $l$ describes the range of the correlation, $\sigma_{n}$ describes the measurement noise, and $\delta_{i j}$ is 1 if $i=j$ and 0 otherwise.

\section{Quantifying of survival and growth conditions influence}

To investigate the influence of complex combination of extracellular conditions on yeast growth kinetic we used the numeric calculation of the OD integral and the O2 integral. The integral was defined as the area under the growth curve or oxygen saturation curve:

OD integral $(\mathrm{OD}, \mathrm{t})=\sum_{i=1}^{n}\left(\frac{1}{2} *\left(\mathrm{OD}_{i}+\mathrm{OD}_{i-1}\right) *\left(\mathrm{t}_{i}-\mathrm{t}_{i-1}\right)\right)$

where $n$ is the total number of discrete time points in the measurement, and in the case of $\mathrm{O} 2$ integral the oxygen saturation of medium was used instead the OD. By using non-parametric GRPR we defined multidimensional model of the OD integral and $\mathrm{O} 2$ integral dependence on quantitative influence of multiple extracellular factors. From the integral dependence on acetic acid concentration we defined the EC50 for the growth or mitochondria inhibition as the amount of acetic acid needed for $50 \%$ of growth or mitochondria respiratory inhibition:

$$
E C_{50}(\mathrm{OD} \text { integral }):=\mathrm{c}(\text { acetic acid })
$$

with

$$
\begin{aligned}
& \text { OD integral }(\mathrm{c}(\text { acetic acid })) \\
& =\frac{\max [\mathrm{OD} \text { integral }]-\min [\mathrm{OD} \text { integral }]}{2}
\end{aligned}
$$

where in the case of EC50 for mitochondria inhibition the O2 integral was used.

To estimate relative growth or mitochondria viability we calculated the area below curves that represent $\mathrm{OD}$ or $\mathrm{O} 2$ integral (calculated from GRPR) dependence on acetic acid concentration and defined these areas as OD toxicity or O2 toxicity integrals. These integrals were further normalized to the highest values for each investigated strain and the resulted normalized parameters were defined as relative growth viability or relative mitochondria viability:

viability(OD integral, c(acetic acid))

$$
\begin{aligned}
=\sum_{i=1}^{n}( & \frac{1}{2} *\left(\mathrm{OD} \text { integral }_{i}+\mathrm{OD}_{\text {integral }}{ }_{i-1}\right) \\
& \left.*\left(\mathrm{c}(\text { acetic } \text { acid })_{i}-\mathrm{c}\left(\text { acetic }_{\text {acid }}\right)_{i-1}\right)\right)
\end{aligned}
$$

where $n$ is the total number of grid points in the multidimensional interpolation space, and in the case of $\mathrm{O} 2$ integral the oxygen saturation of medium was used instead the OD.

\section{RESULTS}

\section{DEPENDENCE OF ACETIC ACID TOXICITY ON THE EXTRACELLULAR pH CONDITIONS}

To study dependence of acetic acid toxicity on the extracellular $\mathrm{pH}$ and glucose concentration we performed an automated multifactorial experiment in which the multidimensional experimental space is generated by an algorithm that sequentially adds parameter combinations maximizing the difference to data points already in the experimental design set. The resulting space filling experimental design covers the entire feasible parameter space evenly. By using a log-scaled axis for glucose concentration, the data points in our experimental design provide a dense coverage of the lower concentration range. The calculation of growth kinetic is performed by piece-wise linear regression of $\log (\mathrm{OD})$ and the maximal growth rate and maximal biomass yield are determined for each measured set of conditions. The obtained results are used to develop a RSM of growth dependence on extracellular glucose concentration and $\mathrm{pH}$ condition by GRPR (see Materials and Methods).

RSMs of cell growth dynamics confirmed a strong shift of optimal $\mathrm{pH}$ conditions from low $\mathrm{pH}$ values toward higher ones in presence of increasing acetic acid concentrations (Figure1). Lack of Hap4p resulted in a slightly reduced growth rate (Figure 1A) and significantly reduced biomass yield (data not shown). Although, the growth of yeast cells under high glucose concentration does not require mitochondrial activity, our results indicate that functional mitochondria and the transcriptional complex Hap 2-3-4-5 are indispensable for optimal growth rates and biomass production. Upon treatment with acetic acid survival is facilitated in conditions that favor the dissociation of acetic acid, e.g., higher $\mathrm{pH}$ environment. However, dissociation to acetate anion and hydrogen ion leads to acidification of the extracellular milieu. If the buffering capacity of the medium $(50 \mathrm{mM}$ citrate/phosphate buffer) is exceeded by high acetic acid concentrations a considerable amount of acetic acid will be present in undissociated form and able to enter the cell. Therefore, the treatment with very high concentrations of acetic acid will cause significant growth reduction even in high extracellular $\mathrm{pH}$ conditions (Figure 1).

The response of $\Delta$ hap4 mutant to acetic acid treatment was significantly different from the response of wild-type cells. Surprisingly, $\Delta$ hap 4 mutant cells could survive in much lower 


\section{y486 wt, y486 $\Delta$ hap4}
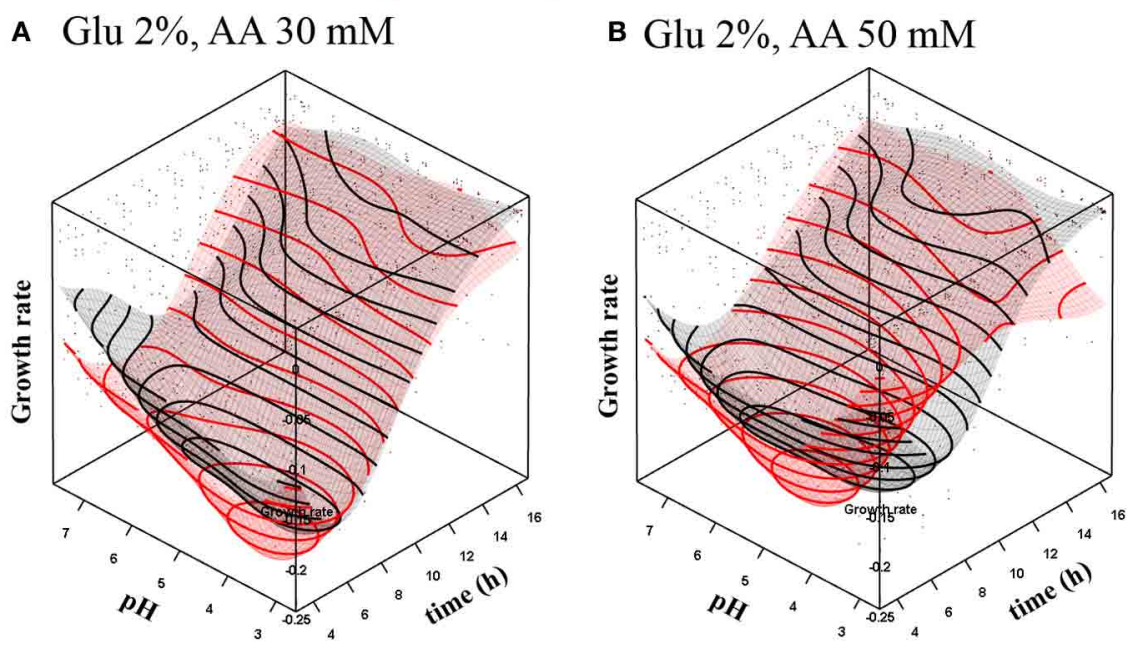

c Glu $2 \%$, AA $80 \mathrm{mM}$

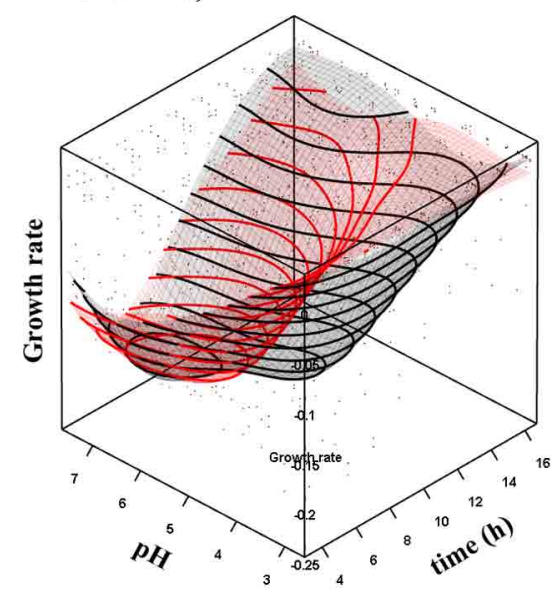

D Glu $2 \%$, AA $120 \mathrm{mM}$

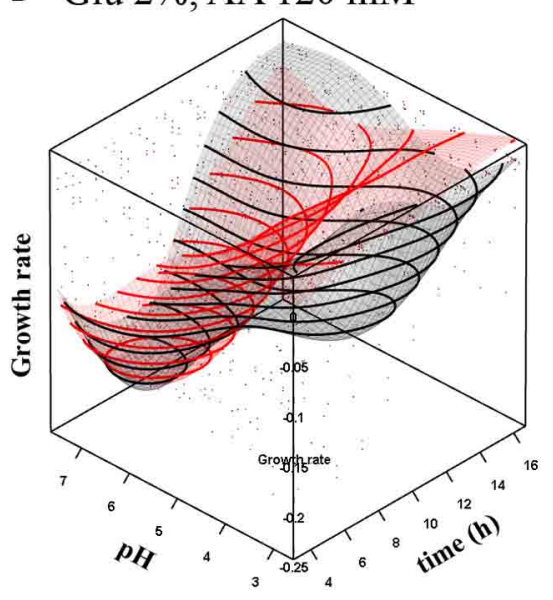

FIGURE 1 | Dependence of growth rate on $\mathrm{pH}$ conditions in YPD medium upon treatment with (A) $30 \mathrm{mM}$ or (B) $50 \mathrm{mM}$, (C) $80 \mathrm{mM}$ and (D) $120 \mathrm{mM}$ acetic acid and constant $2 \%$ glucose concentration. The graphs represent interpolated response surface models of growth rates $(\mu)$ over time in

(black surface). Note: inverted growth scale; the best growth is in the valley. Individual data point in the graph represent single measurements that were base for the interpolation. As the interpolation surface presented in the graph was based on the standard glucose concentration, data points for other glucose concentration conditions lay outside the interpolated surface.

extracellular $\mathrm{pH}$ conditions (Figure 1). The maximal growth rate of the $\Delta$ hap 4 mutant is reached at a later time point of cultivation if cells are grown at lower $\mathrm{pH}$. In contrast, wild-type yeast showed a complete growth inhibition under these conditions. At higher acetic acid concentration (120 mM; Figure 1D) growth rate was also reduced in $\Delta$ hap 4 cells.

Presence of acetic acid in growth medium appeared to be toxic for the mitochondria respiratory activity as well (Figure 2). Based on the measurements of oxygen consumption of cells grown in various combinations of extracellular conditions (see Materials and Methods) we developed a RSM of respiratory activity in dependence of acetic acid, glucose concentration, and extracellular $\mathrm{pH}$. The $\mathrm{O}_{2}$ integral was defined as the area under the oxygen saturation curve over time during the experiment. These values were used for computing the RSM of the acetic acid inhibition of respiratory activity. The inhibition of respiration was clearly concentration and $\mathrm{pH}$ dependent (Figure 2).

The ability of acetic acid to inhibit cell growth or mitochondria activity was characterized as "relative growth viability" or "relative mitochondria viability" by using non-parametric GRPR we defined multidimensional RSM of the OD-integral and $\mathrm{O}_{2}$-integral dependence on multiple extracellular factors (see Materials and Methods). From these models, we calculated the area below curves representing $\mathrm{OD}$ - or $\mathrm{O}_{2}$-integral dependence on acetic acid concentration calculated from RSM for various $\mathrm{pH}$ and glucose concentrations in the medium as OD toxicity or $\mathrm{O}_{2}$ toxicity integrals. These integrals were further normalized to the highest values of each strain investigated to obtain normalized values that we defined as "relative growth viability" or "relative mitochondria viability." With this computational processing we 
obtained numerical values describing the cellular sensitivity to the complex combination of environmental factors that can be presented in 2D graphs with one variable. Our results clearly show the highest toxicity of acetic acid (growth and respiration) in low $\mathrm{pH}$ conditions and lower sensitivity of the $\Delta$ hap4 mutant

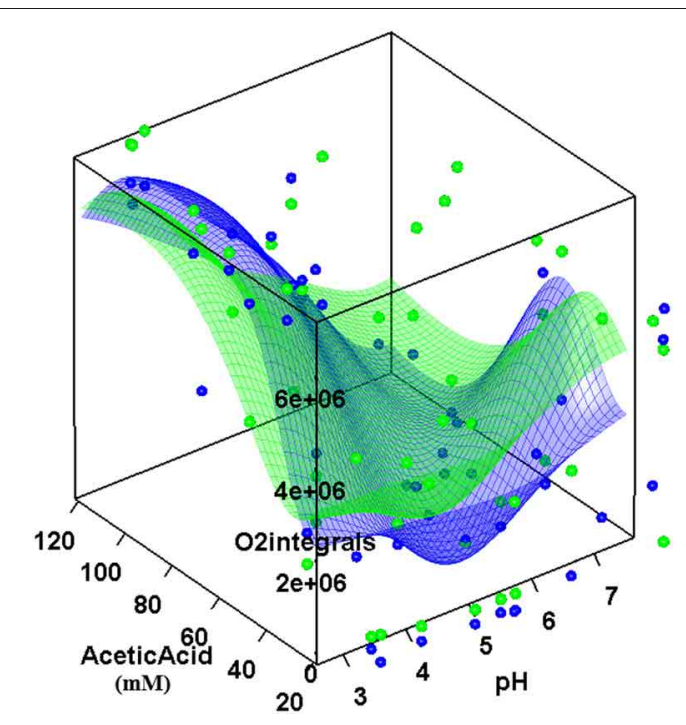

FIGURE 2 | Respiratory activity dependence on acetic acid concentration and extracellular $\mathbf{p H}$. The graphs represent interpolated response surface models (RSM) of $\mathrm{O}_{2}$ integrals, defined as the area under the oxygen saturation curve, in dependence on $\mathrm{pH}$ and acetic acid concentrations for wild-type (blue surface) and hap4 mutant cells (green surface) at a standard glucose concentration in the medium (2\%). Note: high integral represents low oxygen consumption and respiratory inhibition; the best respiratory activity is in the valley. Individual data points in the graph represent single measurements that were the basis for the interpolation. The interpolation surface presented in the graph is based on one glucose concentration, and the data points for other glucose concentrations lay outside the interpolated surface.
(Figure 3). At higher $\mathrm{pH}$ conditions the $\Delta$ hap4 mutant exhibited reduced mitochondrial respiratory activity. Interestingly, inhibition of respiration by acetic acid was comparable between wild-type and $\Delta$ hap4 mutant suggesting that further metabolic alterations, differently regulated in those strains, are responsible for the increased resistance of the mutant strain to acetic acid (Figure 3B).

\section{INCREASED GLUCOSE CONCENTRATION PROTECTS CELLS AGAINST ACETIC ACID TOXICITY}

Growth rate of yeast cells at pH 3.0, in the presence of very low, non-toxic concentrations $(30 \mathrm{mM})$ of acetic acid, progressively increased over time, reaching a maximum after about $5 \mathrm{~h}$ of cultivation (Figure 4A). After this time point growth rate was decreasing as nutrient supply was depleted and metabolic by-products accumulated. Increasing glucose concentration (up to $2 \%$ ) had a stimulating effect on the growth rate. The optimum glucose concentration under these conditions was between $2 \%$ and $4 \%$. Both, wild-type and $\Delta$ hap4 mutant, showed a similar growth dependence on glucose in the medium. Interestingly, when acetic acid concentration was increased to $50 \mathrm{mM}$ (Figure 4B), the optimum glucose concentration also increased, with the optimum being above $3.5 \%$. In $\Delta$ hap 4 cells, however, acetic acid did not trigger a shift in optimal glucose levels in the medium, although, the toxic influence of acetic acid, observed as decreased growth rate and delayed time when maximal growth rate is reached, was similar in both strains.

To quantify the protective effect of increased extracellular glucose concentrations on the cellular sensitivity to acetic acid we used the interpolated RSM of the OD integral and $\mathrm{O}_{2}$ integral to visualize the influence of multiple extracellular factors. From the integral of the dependence on acetic acid concentration we defined the specific EC50 as the amount of acetic acid needed for $50 \%$ of growth or mitochondria respiratory inhibition. As mentioned before, we also calculated the area below curves that represent $\mathrm{OD}$ or $\mathrm{O}_{2}$ integral dependence on acetic

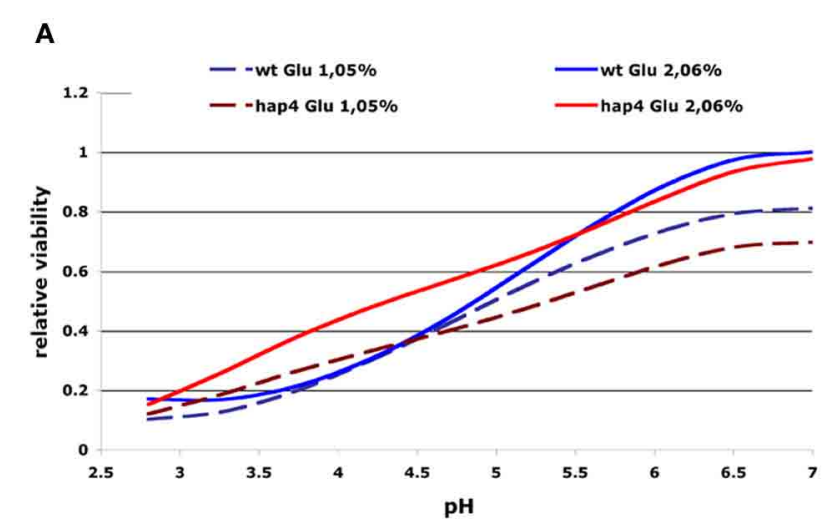

FIGURE 3 | 2D presentation of calculated "relative growth viability" (A) and "relative mitochondrial viability" (B) upon acetic acid treatments in dependence on extracellular $\mathrm{pH}$ and glucose concentration. The curves represent the $\mathrm{OD} / \mathrm{O}_{2}$-integral dependence on acetic acid concentration calculated from $\mathrm{RSM}$ for the whole range of $\mathrm{pH}$ values ( $x$-axis) and were normalized to the highest values for each investigated

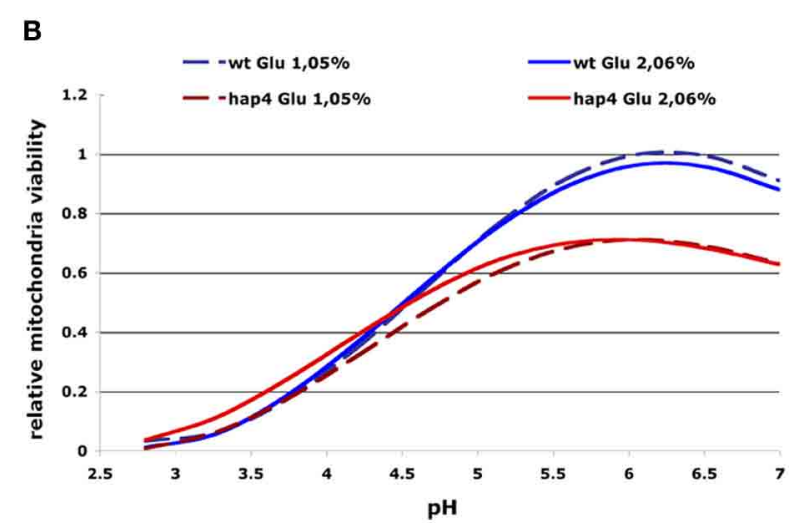

strain. Results for selected glucose concentrations and strains are presented as indicated. The resulting normalized values were defined as "relative growth viability" and "relative mitochondria viability" (see Materials and Methods). Sensitivity to acetic acid is clearly reduced in the hap4 mutant at lower $\mathrm{pH}$, while impaired mitochondrial activity of the $\Delta$ hap4 mutant can be seen at higher $\mathrm{pH}$. 


\section{A $\quad \mathrm{pH} 3.0, \mathrm{AA} 30 \mathrm{mM}$}

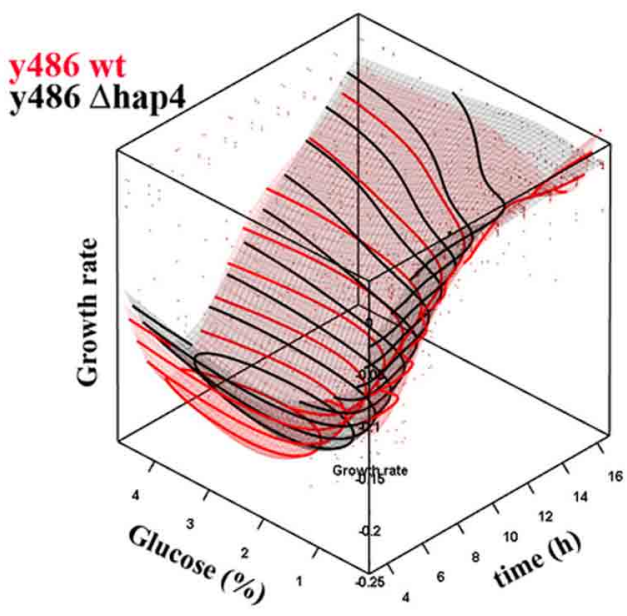

FIGURE 4 | Dependence of growth rate on glucose concentration in YPD medium upon treatment with (A) $30 \mathrm{mM}$ or (B) $50 \mathrm{mM}$ acetic acid (AA) at $\mathbf{p H}$ 3.0. The graphs represent response surface models of growth rates $(\mu)$ over time in dependence on glucose concentration for wild-type (red surface) and hap4 mutant cells (black surface). Note: inverted growth

\section{B}

\section{$\mathrm{pH} 3.0, \mathrm{AA} 50 \mathrm{mM}$}

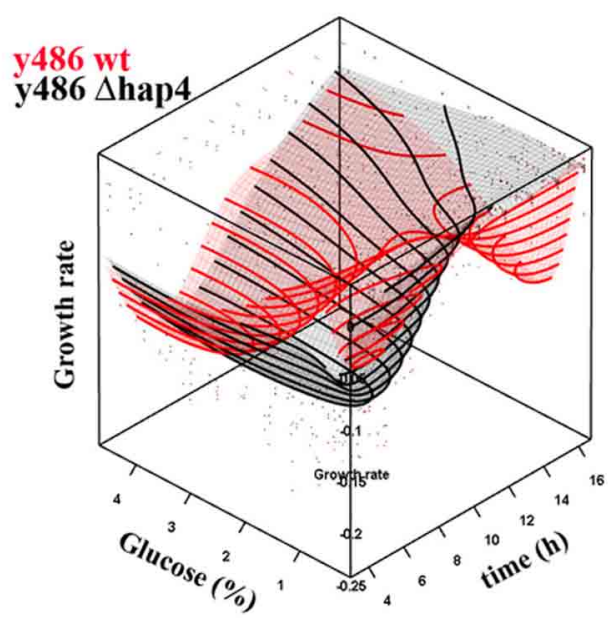

scale; the best growth is in the valley. Individual data points in the graph represent single measurements that were used for the interpolation. The interpolation surface presented in the graph is based on one $\mathrm{pH}(\mathrm{pH} 3.0)$, and data points for the other $\mathrm{pH}$ conditions lay outside the interpolated surface. acid concentration calculated from RSM for various $\mathrm{pH}$ and glucose concentrations in the medium and defined these areas as $\mathrm{OD}$ toxicity or $\mathrm{O}_{2}$ toxicity integrals. As before, results were normalized to the highest values for each investigated strain and the resulting normalized parameters were again defined as "relative growth viability" or "relative mitochondria viability." The results show that increasing extracellular glucose concentrations resulted in an increased EC50 for growth inhibition and inhibition of mitochondrial respiration in both investigated strains (Figures 5A,C). The data also indicate a steady increase of EC 50 values for both, growth and mitochondria inhibition, with increased extracellular $\mathrm{pH}$ (Figures 5A,C). These results were also reflected in an increase of "relative growth viability" at high extracellular glucose or $\mathrm{pH}$ conditions (Figure 5B). However, "relative mitochondria viability" was decreased at elevated glucose concentrations in the medium as a result of decreased aerobic and increased fermentative metabolism (Figure 5D).

\section{EFFECT OF ACETIC ACID ON GLUCOSE UPTAKE AND CARBOHYDRATE STORAGE}

Glucose-repressed cells are impermeable to the anion (Cássio et al., 1987) and only the undissociated form of acetic acid is able to enter the cells by simple diffusion. Acetic acid affects the transport of glucose by acting on the transport proteins as uncoupler dissipating $\Delta \mathrm{pH}$ and membrane potential (Sousa et al., 1995). Our results show that acetic acid significantly inhibited mitochondria respiration (Figure 2). The inhibitory effect on mitochondria can be explained as a result of respiratory chain uncoupling and an impinging effect on the $\Delta \Psi$.

In order to test whether glucose consumption directly depends on the concentration of acetic acid we performed time-course measurements of glucose concentration in presence of increasing concentrations of acetic acid. The results confirmed an acetic acid concentration-dependent inhibition of glucose uptake (Figure 6A). Surprisingly, the inhibitory effect of acetic acid observed was much lower in the $\Delta$ hap4 mutant. Although reduced, glucose consumption was still detected in $\Delta$ hap4 mutant treated with $50 \mathrm{mM}$ acetic acid. In contrast, wild-type cells treated with the same acetic acid concentration completely ceased glucose consumption already after $2 \mathrm{~h}$ of treatment (Figure 6A). Moreover, the inhibition of growth by acetic acid was reciprocally proportional to the inhibition of glucose consumption (Figure 6B). Thus, sustained glucose uptake in $\Delta$ hap4 mutant supported cell growth even in the presence of $50 \mathrm{mM}$ acetic acid.

Respiratory deficient cells exhibit high level of glycogen and trehalose accumulation (Enjalbert et al., 2000; Kitanovic et al., 2009). In general, various types of stress, like nutrient starvation, heat-shock, or oxidative stress, induce futile cycling of storage carbohydrates, trehalose and glycogen, meaning that both biosynthesis and biodegradation pathways are activated almost to the same extend (Parrou and Francois, 1997). Glycogen and preferentially trehalose, serve as a fuel reserve that enable yeast cells to survive starvation. Upon return to favorable conditions or upon defeating stress conditions these storage carbohydrates can be quickly mobilized to help fuel growth (Shi et al., 2010). However, in conditions where glucose uptake is inhibited by acetic acid, increased synthesis of glycogen and trehalose would create significant energy deficiency and dissipation of important metabolic intermediates that could be used in catabolic reactions to sustain sufficient levels of ATP within cells. To test this hypothesis, we measured glycogen and trehalose accumulation upon treatment of wild-type and $\Delta$ hap 4 mutant with increasing acetic acid concentrations. The experiments showed that acetic acid treatment caused significant accumulation of both, glycogen and trehalose only in wild-type cells (Figures 6C,D). In the $\Delta$ hap4 mutant 


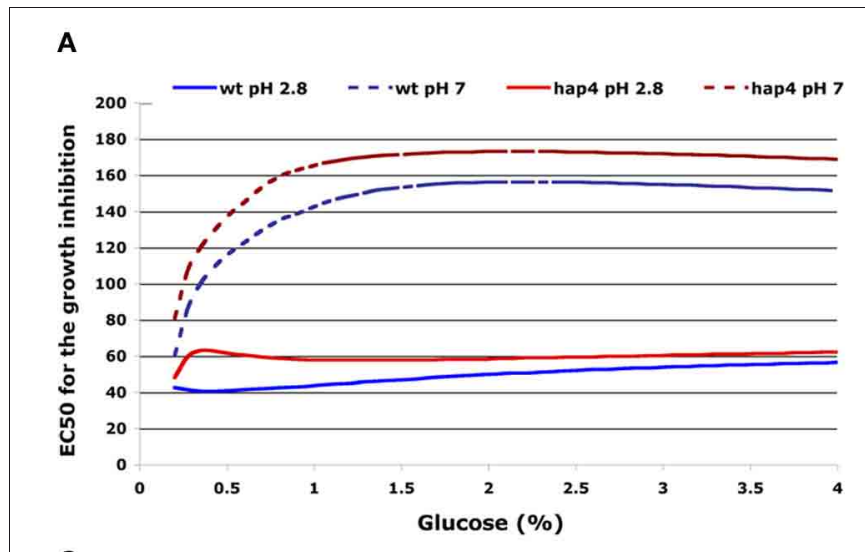

C

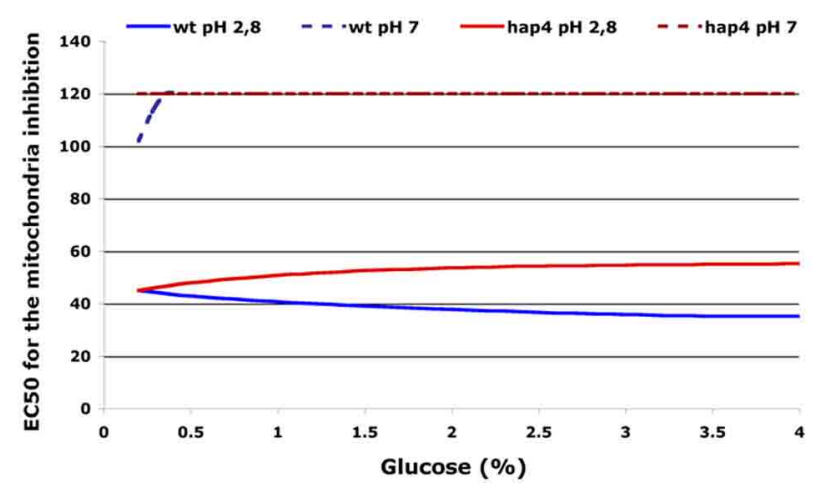

FIGURE 5 | 2D presentation of calculated EC50 for growth inhibition (A) or inhibition of respiration (B) and "relative growth viability" (C) or "relative mitochondria viability" (D) upon acetic acid treatment in dependence on glucose concentration and extracellular pH. The EC50 for growth or

mitochondria inhibition was defined by the integral dependence on acetic acid
B

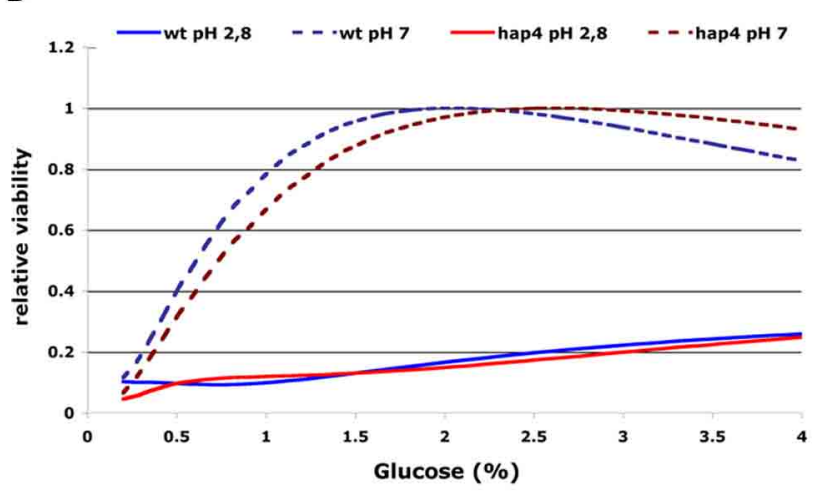

D

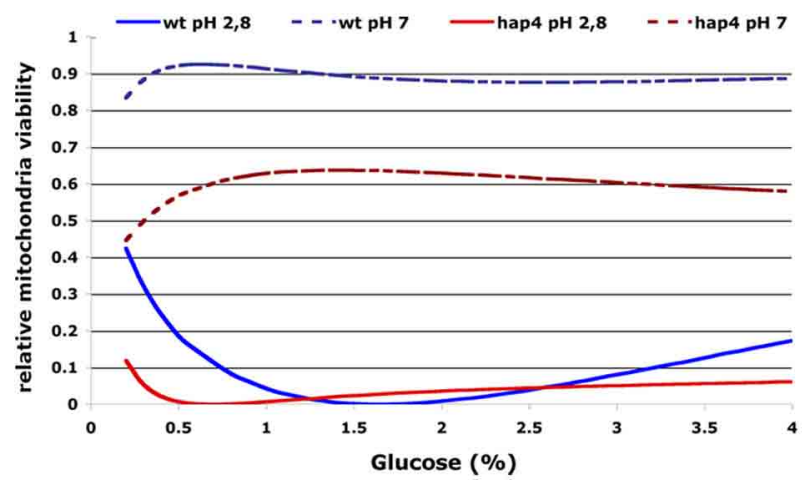

concentration as the amount of acetic acid needed for $50 \%$ of growth or mitochondria respiratory inhibition. "Relative growth viability" or "relative mitochondria viability" were defined as the normalized values that represent $\mathrm{OD} / \mathrm{O}_{2}$-integral dependence on acetic acid concentration (see Materials and Methods). Results for selected $\mathrm{pH}$ values and strains are presented as indicated. we detected increased levels of these storage carbohydrates only at the onset of glucose exhaustion, the conditions which normally facilitate their accumulation. A short, transient increase of trehalose and glycogen levels followed by their fast mobilization was observed in $\Delta$ hap 4 mutant only after treatment with very high acetic acid concentrations ( $80 \mathrm{mM}$; Figures 6C,D).

\section{INTRACELLULAR ACIDIFICATION AND GLYCOLYTIC FLUX UPON ACETIC ACID TREATMENT}

Yeast cells are unable to maintain a stable $\mathrm{pH}$ gradient across the plasma membrane on starvation (Dechant et al., 2010). It was shown earlier that reduced glycolytic flux upon starvation directly results in significant acidification of the cytosol (Dechant et al., 2010) as a consequence of ATP depletion. For ATPase to accomplish its function of regulating internal $\mathrm{pH}$ ( $\mathrm{pHin}$ ), metabolic activity and sustainable level of ATP is required. Therefore, it is to be expected that increased glucose concentration in the medium could help to keep sufficient ATP level for ATPase function and prevent intracellular acidification.

To investigate alterations of intracellular $\mathrm{pH}$ upon acetic acid treatment we performed in vivo monitoring of cytosolic $\mathrm{pH}$ using ratiometric measurements with pHluorin that exhibits $\mathrm{pH}$ dependent dual excitation peaks at 395 and $475 \mathrm{~nm}$ (Braun et al.,
2010). Cells containing reporter plasmid were grown in minimal SD medium with different glucose concentrations in presence or absence of $40 \mathrm{mM}$ acetic acid. In control culture grown in extracellular $\mathrm{pH} 3.0$ and $2 \%$ glucose a fast drop of intracellular $\mathrm{pH}$ was observed in the late stationary phase (Figure 7). Acetic acid treatment under these conditions resulted in much earlier cytosolic acidification already after $20 \mathrm{~h}$ of treatment probably as a consequence of ATP depletion following inhibition of glucose uptake (as shown in Figure 6A). Cultivation of cells in $4 \%$ glucose medium could prevent intracellular acidification in both control and acetic acid treated cells. In contrast, decrease of glucose concentration in medium resulted in rapid cytosolic acidification at a much earlier time point of cultivation independently of acetic acid. These results confirmed that maintenance of intracellular $\mathrm{pH}$ depends on glucose signaling. In conditions of glucose exhaustion in the medium or inhibition of glucose uptake by acetic acid, the intracellular ATP pool becomes limited and-as a consequence-disturbs the $\mathrm{pH}$ balance, significantly reducing cytosolic $\mathrm{pH}$.

Dechant et al. (2010) showed that changes in the ATP level directly impinge on cytosolic $\mathrm{pH}$, which acts as a second messenger in response to glucose. A similar mechanism of glucose sensing was described in pancreatic $\beta$-cells, in which increasing 

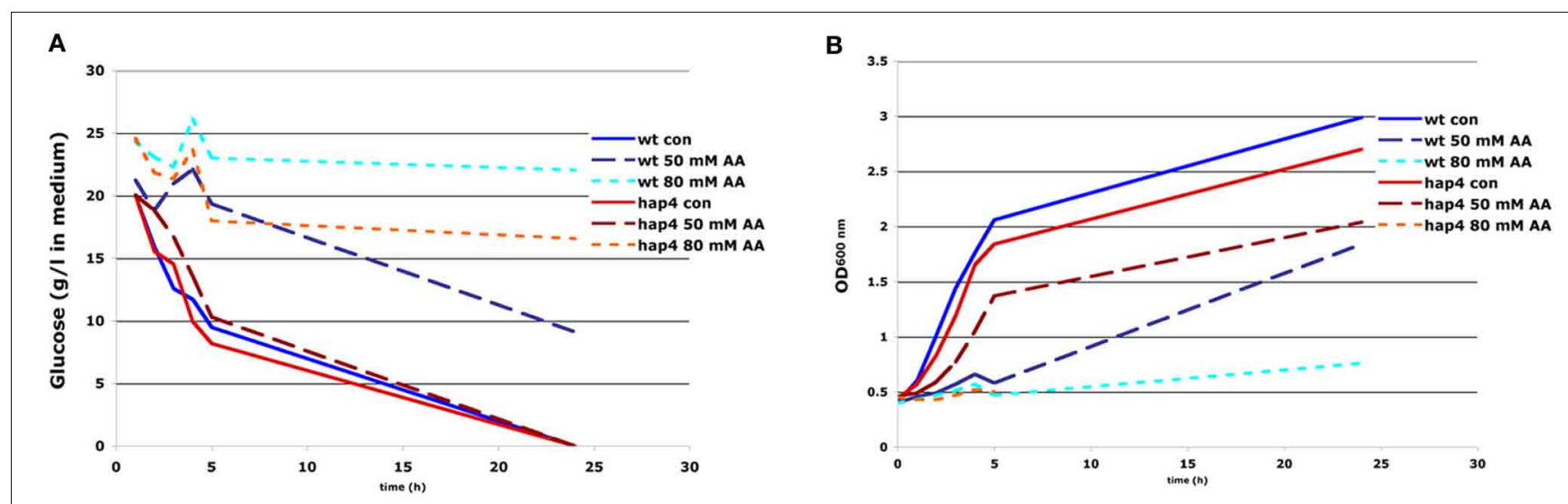

C

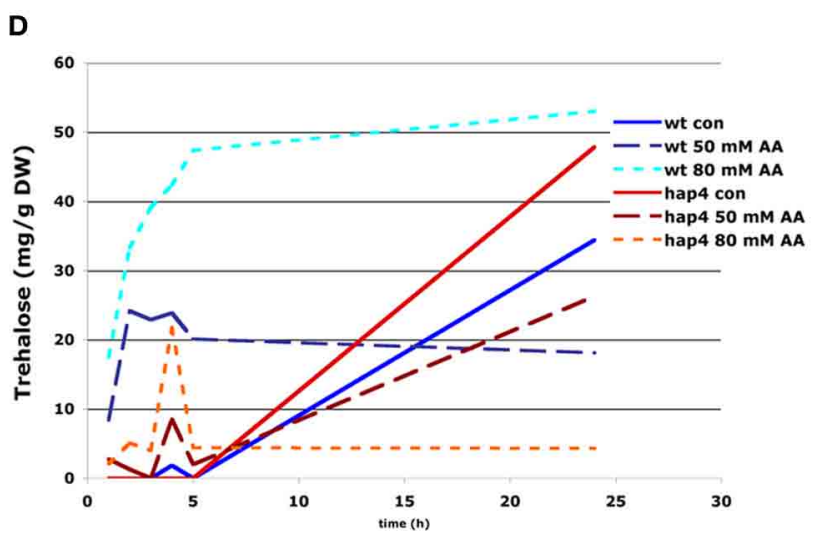

FIGURE 6 | Effect of acetic acid treatment on cell growth, glucose consumption, and accumulation of glycogen and trehalose. FF18984 wild-type and hap4 mutant cells were cultured to mid-log phase $\left(\mathrm{OD}_{600}=0.6-1.0\right)$ in full (YPD) medium either mock- (control) or acetic

\section{acid-treated (AA) with concentration of 30,50 , and $80 \mathrm{mM}$ of AA. Glucose content in the medium (A), optical density of the culture $\left(O D_{600}\right)(\mathbf{B})$, and kinetics of glycogen (C) and trehalose (D) accumulation were monitored during $26 \mathrm{~h}$ of cultivation.}

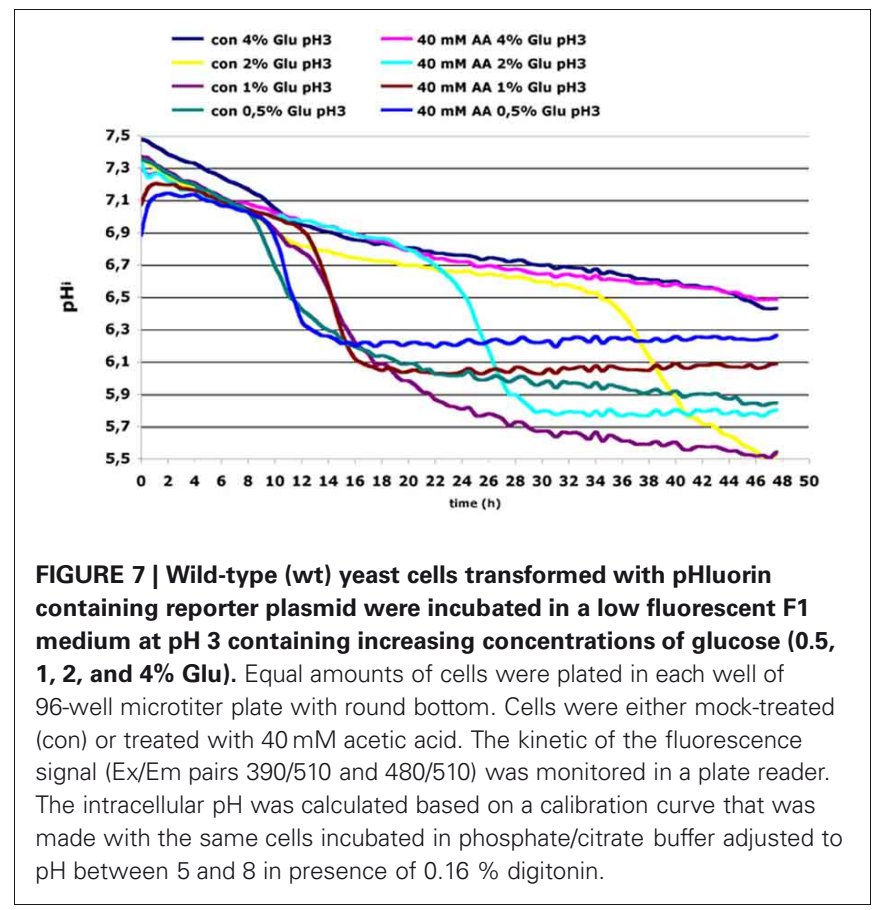

ATP concentrations mediate glucose sensing through inactivation of ATP-dependent $\mathrm{K}^{+}$channels (MacDonald and Wheeler, 2003). Our results show that trehalose and glycogen were synthesized in acetic acid treated cells even in absence of glucose uptake. Together with the observation of Almeida et al. (2009) that amino acids pools are significantly reduced as a consequence of acetic acid treatment, it can be concluded that acetic acid treatments should lead to gluconeogenesis and consumption of glycolytic and tricarboxilic acid pathway (TCA) intermediates in favor of storage carbohydrate synthesis.

To test this hypothesis we analyzed the activity of glycolytic and TCA pathway enzymes upon treatment with $50 \mathrm{mM}$ acetic acid in wild-type and the $\Delta$ hap4 mutant. The results obtained (Figures 8A-C) show a significant increase in the activity of the glycolytic enzymes PYK, GAPDH, and G6PDH activity in both wild-type and $\Delta$ hap4 mutant cells. Higher concentration of acetic acid (from $80 \mathrm{mM}$ ) significantly inhibited the activity of all three enzymes (data not shown). The activity of the TCA pathway enzymes $\mathrm{MDH}$, and IDH, and the key enzyme in gluconeogenesis, FBP1, however, was elevated only in wild-type cells. The $\Delta$ hap4 mutant showed significantly reduced activity of those enzymes in both control and acetic acid treated cells. 


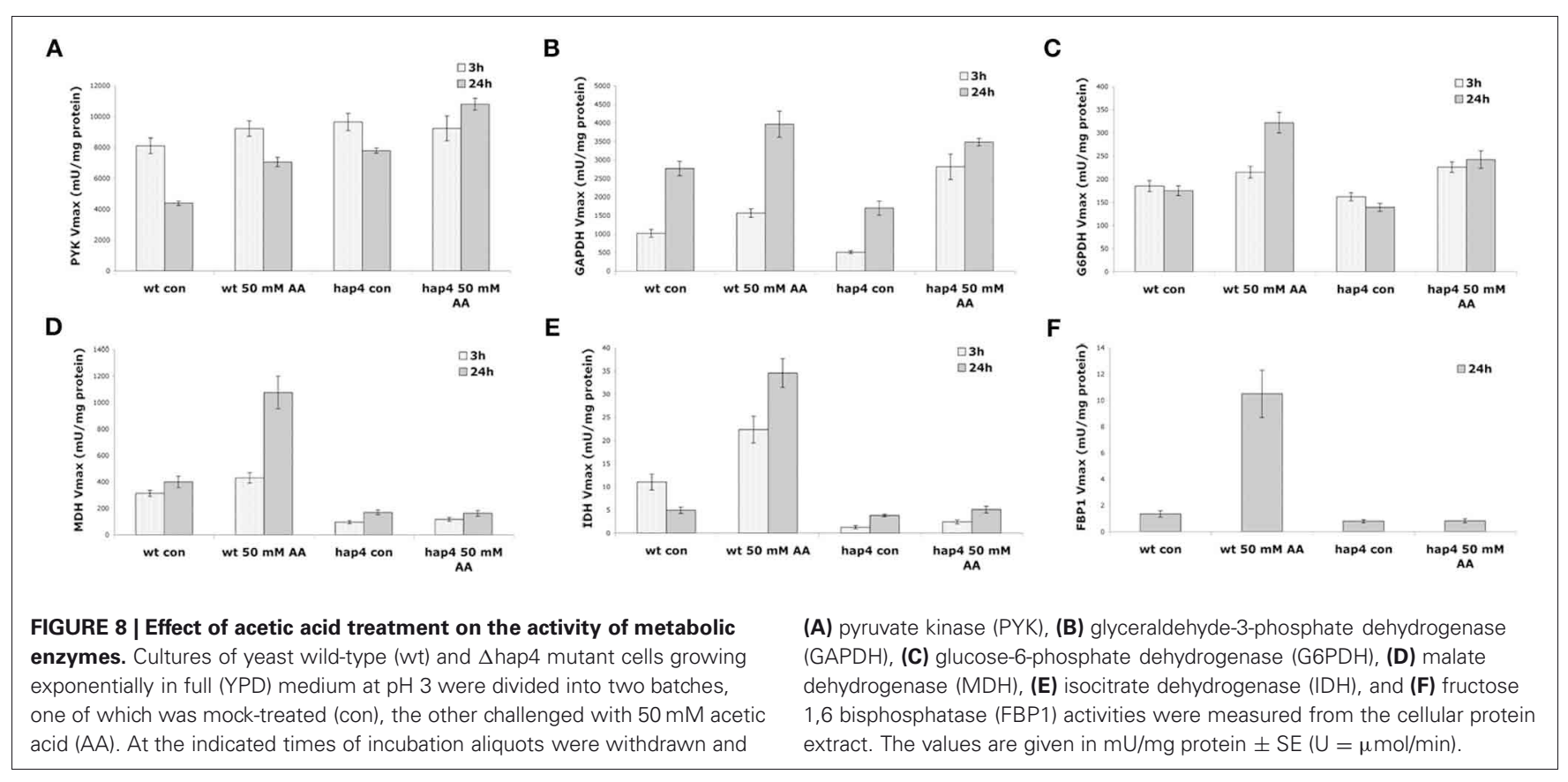

The yeast Saccharomyces cerevisiae adapts to glucose exhaustion through induced transcription of genes involved in various cellular processes, including gluconeogenesis, the glyoxylate cycle, the tricarboxylic acid (TCA) cycle, respiration, $\beta$-oxidation, and utilization or transport of alternative sugars. Enzymes of gluconeogenesis and the glyoxylate cycle are indispensable for growth on non-fermentable carbon sources, such as, ethanol, lactate, or glycerol (Schüller, 2003). Hap4p is a subunit of the Hap2/3/4/5 transcriptional complex, which is involved in the transcriptional regulation of TCA cycle genes, glyoxylate cycle genes and stress response genes (Raghevendran et al., 2006). Hap4p overexpression results in increased growth rates and biomass formation and prolonged life span (Lin et al., 2002). Therefore, decreased toxicity of acetic acid in $\Delta$ hap4 mutant could be explained by lower inhibition of glucose uptake and, in parallel, decreased activity of gluconeogenesis, TCA cycle, and synthesis of storage carbohydrates. This would result is increased ATP levels that could support the function of membrane ATPases in maintaining intracellular $\mathrm{pH}$ homeostasis and prevent amino acids starvation.

\section{DISCUSSION}

The accumulation of acetic acid in stationary phase budding yeast cultures is considered to be the primary mechanism of chronological aging in yeast and recent results suggest that the mechanism of acetic acid toxicity in yeast could be related to the induction of growth signaling pathways and oxidative stress (Burhans and Weinberger, 2009; Burtner et al., 2009). Recent publications showed that buffering medium could inhibit the agedependent accumulation of reactive oxygen species preferentially superoxide anions that is produced by dysfunctional mitochondria (Burhans and Weinberger, 2009; Pan et al., 2011). The accumulation of acetic acid in stationary phase induces oxidative stress, a factor previously implicated in chronological aging of yeast and aging in other organisms as well. Interestingly, the

accumulation of acetic acid in stationary phase cultures inhibits growth arrest of cells in G1 and is preferentially toxic to cells that fail to undergo a G1 arrest (Burhans and Weinberger, 2009).

We used a multifactorial experimental design to investigate the impact of acetic acid on cellular growth kinetics in dependence on glucose concentration as well as extracellular $\mathrm{pH}$, covering the whole range of combinations in experimental conditions. Raising the extracellular $\mathrm{pH}$ clearly reduced the toxic influence of acetic acid. The accumulation of undissociated acids within the cell is a function of $\Delta \mathrm{pH}$ and glucose concentration in the medium (Thomas et al., 2002). By raising the $\mathrm{pH}$ to a value higher than the $\mathrm{pKa}$ of the acid, the concentration of undissociated acid is reduced for a given amount of total acid, placing less stress on cells. Raising the extracellular glucose concentration results in increased intracellular ATP supporting the activity of ATPases (Thomas et al., 2002). Both conditions result in a lower waste of energy for maintenance of the pHin in the range optimal for growth. The outcome is a decreased inhibitory effect of acetic acid on yeast growth and metabolism.

The protecting effect of high glucose concentrations observed in our experiments could be explained by several mechanisms. Acetic acid can enter the cells only in its undissociated, uncharged form. The charged acetate anion is generally considered as non-toxic (Piper et al., 2001). A higher $\mathrm{pH}$ on the cytosolic side of the membrane can cause a substantial fraction of this acid to dissociate to the anion, a form which is relatively membrane-impermeable and that therefore will accumulate inside the cell resulting in intracellular acidification (Piper et al., 2001).

In budding yeast and many other fungi, intracellular acidification activates highly conserved Ras2 and cAMP-dependent signaling pathways that respond to glucose (Thevelein and de Winde, 1999). Thus, despite the oxidative stress, inhibition of 
glycolysis, induction of gluconeogenesis and synthesis of storage carbohydrates, acetic acid treated cells are continuously subjected to growth signals that promote entry into $S$ phase. Constitutive activation of the Ras-cAMP-PKA pathway would also result in a PKA-dependent loss of mitochondrial function (Gourlay and Ayscough, 2006), which requires HAP4 transcriptional regulation and accumulation of damaged, high ROS producing mitochondria (Leadsham and Gourlay, 2010). The result is a conflicting situation. On one side, inhibition of glucose uptake and mitochondria function by acetic acids will result in significant ATP depletion and disturbed $\mathrm{pH}$ homeostasis. Available nutrients are then redirected toward synthesis of storage carbohydrates causing insufficient synthesis of dNTPs and inefficient DNA replication. On the other side, Ras-cAMP-PKA activation will stimulate growth. Together, intracellular acid accumulation seems to trigger an inappropriate growth signal and replication stress, which leads to cell death. Feeding with high glucose concentrations can, therefore, prevent the energetic collapse in mitochondria impaired cells where the glycolytic flux is reduced because of low $\mathrm{pH}$. This also fits with the observation that neutralizing buffering of yeast media could extend chronological life span in yeast cells, implicating that other mechanism than just simple acidification of the environment are involved in acetic acid-induced metabolic alterations and apoptosis induction (Pan et al., 2011).

Reduced sensitivity of the $\Delta$ hap 4 mutant to acetic acid may be explained by impaired expressions of gluconeogenic, glyoxylate, and TCA cycle enzymes, which are regulated by the Hap 2-3-4-5 complex (Figure 8). The low gluconeogenic activity in the $\Delta$ hap 4 mutant will prevent the synthesis of storage carbohydrates, trehalose and glycogen, in conditions where glucose uptake is inhibited by acetic acid. Lin et al. (2002) showed that aged cells respond to glucose-deprivationbyshifting themetabolismawayfromglycolysis toward gluconeogenesis and energy storage. In acetic acid induced aging, increased gluconeogenesis and trehalose/glycogen synthesis pathways will compete with amino acids synthesis pathways

\section{REFERENCES}

Almeida, B., Ohlmeier, S., Almeida, A. J., Madeo, F., Leão, C., Rodrigues, F., and Ludovico, P. (2009). Yeast protein expression profile during acetic acid-induced apoptosis indicates causal involvement of the TOR pathway. Proteomics 9, 720-732.

Bonowski, F., Kitanovic, A., Ruoff, P., Holzwarth, J., Kitanovic, I., Bui, V. N., Lederer, E., and Wölfl, S. (2010). Computer controlled automated assay for comprehensive studies of enzyme kinetic parameters. PLoS ONE 5:e10727. doi: 10.1371/journal.pone.0010727

Bradford, M. M. (1976). A rapid and sensitive method for the quantitation of microgram quantities of protein utilizing the principle of protein-dye binding. Anal. Biochem. $72,248-254$.

Braun, N. A., Morgan, B., Dick, T. P., and Schwappach, B. (2010).
The yeast CLC protein counteracts vesicular acidification during iron starvation. J. Cell. Sci. 123, 2342-2350.

Burhans, W. C., and Weinberger, M. (2009). Acetic acid effects on aging in budding yeast: are they relevant to aging in higher eukaryotes? Cell Cycle 8, 2300-2302.

Burtner, C. R., Murakami, C. J., Kennedy, B. K., and Kaeberlein, M. (2009). A molecular mechanism of chronological aging in yeast. Cell Cycle 8, 1256-1270.

Cássio, F., Leão, C., and van Uden, N. (1987). Transport of lactate and other short-chain monocarboxylates in the yeast Saccharomyces cerevisiae. Appl. Environ. Microbiol. 53, 509-513.

Cramp, D. G. (1967). New automated method for measuring glucose by glucose oxidase. J. Clin. Pathol. 20, 910-912.

for the same glycolytic and TCA intermediates. In consequence, this will result in a condition of amino acids starvation and ATP depletion. In contrast, in the $\Delta$ hap 4 mutant the limited available glucose in the cells can be fully used for sustaining the ATP pool and pHin homeostasis and significantly decrease acetic acid toxicity.

Our results clearly show the interdependence between an important metabolic by-product of yeast fermentation, acetic acid, and the efficiency of the cellular metabolism as well as aging of cells. In addition to providing some new insight into the role of extracellular conditions and availability of nutrients on glucose metabolism, respiration, cellular proliferation and aging, which play a central role in different diseases, our results also suggest controlled stress conditions as a means to increase fermentation efficiency. Given the urgent need to optimize the production of fuel ethanol from cellulosic biomass as a more environmentalfriendly fossil fuel alternative, our results suggest that investigating the role of metabolic by products and other stress conditions on fermentation could still lead to further optimization.

\section{AUTHOR CONTRIBUTIONS}

Ana Kitanovic and Stefan Wölfl planed and designed the project. Felix Bonowski conceived and designed the computational framework, Ana Kitanovic, Florian Heigwer, Igor Kitanovic, and Christin Ungewiss designed and performed experiments, Ana Kitanovic, Florian Heigwer, Peter Ruoff, and Stefan Wölfl modeled experimental results, Ana Kitanovic, Igor Kitanovic, and Stefan Wölfl wrote the manuscript.

\section{ACKNOWLEDGMENTS}

We thank Tobias Dick for pHluorin expression plasmids and Hans Westerhoff for support and coordination of the SysMo MOSES Network. This work was supported by the SysMO Project Network (EU-BMBF) on Systems Biology of Microorganisms (MOSES, WP 4.3, Stefan Wölfl and Ana Kitanovic) and DFGFOR630 (Stefan Wölfl and Igor Kitanovic).

Cressie, N. A. C. (1993). Statistics for Spatial Data. New York, NY: Wiley-Interscience.

Dechant, R., Binda, M., Lee, S. S., Pelet, S., Winderickx, J., and Peter, M. (2010). Cytosolic pH is a second messenger for glucose and regulates the PKA pathway through V-ATPase. EMBO J. 29, 2515-2526.

Enjalbert, B., Parrou, J. L., Vincent, O., and François, J. (2000). Mitochondrial respiratory mutants of Saccharomyces cerevisiae accumulate glycogen and readily mobilize it in a glucose-depleted medium. Microbiology 146(Pt 10), 2685-2694.

Fereidouni, M., Daneshi, A., and Younesi, H. (2009). Biosorption equilibria of binary $\mathrm{Cd}(\mathrm{II})$ and $\mathrm{Ni}(\mathrm{II})$ systems onto Saccharomyces cerevisiae and Ralstonia eutrophe cells: application of response surface methodology. J. Hazard. Mater. 168, 1437-1448
Gourlay, C. W., and Ayscough, K. R. (2006). Actin-induced hyperactivation of the Ras signaling pathway leads to apoptosis in Saccharomyces cerevisiae. Mol. Cell. Biol. 26, 6487-6501.

Jones, D. R. (2001). A taxonomy of global optimization methods based on response surfaces. J. Glob. Optim. 21, 345-383.

Kitanovic, A., Walther, T., Loret, M. O., Holzwarth, J., Kitanovic, I., Bonowski, F., Bui, V. N., Francois, J. M., and Wölfl, S. (2009). Metabolic response to MMS-mediated DNA damage in Saccharomyces cerevisiae is dependent on the glucose concentration in the medium. FEMS Yeast Res. 9, 535-551.

Kitanovic, A., and Wölfl, S. (2006). Fructose-1, 6-bisphosphatase mediates cellular responses to DNA damage and aging in Saccharomyces cerevisiae. Mutat. Res. 594, 135-147. 
Kovárová-Kovar, K., and Egli, T. (1998). Growth kinetics of suspended microbial cells: from singlesubstrate-controlled growth to mixed-substrate kinetics. Microbiol. Mol. Biol. Rev. 62, 646-666.

Leadsham, J. E., and Gourlay, C. W. (2010). cAMP/PKA signaling balances respiratory activity with mitochondria dependent apoptosis via transcriptional regulation. $B M C$ Cell Biol. 11, 92.

Lin, S. J., Kaeberlein, M., Andalis, A. A., Sturtz, L. A., Defossez, P. A., Culotta, V. C., Fink, G. R., and Guarente, L. (2002). Calorie restriction extends Saccharomyces cerevisiae lifespan by increasing respiration. Nature 418, 344-348.

Ludovico, P., Rodrigues, F., Almeida, A., Silva, M. T., Barrientos, A., and Côrte-Real, M. (2002). Cytochrome c release and mitochondria involvement in programmed cell death induced by acetic acid in Saccharomyces cerevisiae. Mol. Biol. Cell 13, 2598-2606.

MacDonald, P. E., and Wheeler, M. B. (2003). Voltage-dependent $\mathrm{K}(+)$ channels in pancreatic beta cells: role, regulation and potential as therapeutic targets. Diabetologia 46, 1046-1062.

Marcotte, D. (1995). Generalized cross-validation for covariance model selection. Math. Geol. 27, 0882-8121.

Narendranath, N. V., and Power, R. (2005). Relationship between $\mathrm{pH}$ and medium dissolved solids in terms of growth and metabolism of lactobacilli and Saccharomyces cerevisiae during ethanol production. Appl. Environ. Microbiol. 71, 2239-2243.

Pan, Y., Schroeder, E. A., Ocampo, A., Barrientos, A., and Shadel, G. S. (2011). Regulation of yeast chronological life span by TORC1 via adaptive mitochondrial ROS signaling. Cell Metab. 13, 668-678.

Parrou, J. L., and Francois, J. M. (1997). A simplified procedure for a rapid and reliable assay of both glycogen and trehalose in whole yeast cells. Anal. Biochem. 248, 186-188.

Pereira, C., Camougrand, N., Manon, S., Sousa, M. J., and Côrte-Real, M. (2007). ADP/ATP carrier is required for mitochondrial outer membrane permeabilization and cytochrome c release in yeast apoptosis. $\mathrm{Mol}$. Microbiol. 66, 571-582.

Piper, P., Calderon, C. O., Hatzixanthis, K., and Mollapour, M. (2001). Weak acid adaptation: the stress response that confers yeasts with resistance to organic acid food preservatives. Microbiology 147, 2635-2642.

Popa, O., Babeanu, N., Vamanu, A., and Vamanu, E. (2007). The utilization of the response surface methodology for the optimization of cultivation medium and growth parameters in the cultivation of the yeast strain S. cerevisiae on ethanol. Afr. J. Biotechnol. 6, 2700-2707.

Raghevendran, V., Patil, K. R., Olsson, L., and Nielsen, J. (2006). Hap4 is not essential for activation of respiration at low specific growth rates in Saccharomyces cerevisiae. J. Biol. Chem. 281, 12308-12314.

Rasmussen, C. E., and Williams, C. K. I. (2006). Gaussian Processes for Machine Learning. Cambridge, MA, USA: MIT Press.

Schüller, H. J. (2003). Transcriptional control of nonfermentative metabolism in the yeast Saccharomyces cerevisiae. Curr. Genet. 43, 139-160.

Shi, L., Sutter, B. M., Ye, X., and Tu, B. P. (2010). Trehalose is a key determinant of the quiescent metabolic state that fuels cell cycle progression upon return to growth. Mol. Biol. Cell 21, 1982-1990.

Singh, R., Singh, H., and Saini, G. K. (2009). Response surface optimization of the critical medium components for pullulan production by Aureobasidium pullulans FB1. Appl. Biochem. Biotechnol. 152, 42-53.

Sousa, M. J., Mota, M., and Leão, C. (1995). Effects of ethanol and acetic acid on the transport of malic acid and glucose in the yeast Schizosaccharomyces pombe implications in wine deacidification. FEMS Microbiol. Lett. 126, 197-202.

Thevelein, J. M., and de Winde, J. H. (1999). Novel sensing mechanisms and targets for the cAMPprotein kinase A pathway in the yeast Saccharomyces cerevisiae. Mol. Microbiol. 33, 904-918.
Thomas, K. C., Hynes, S. H., and Ingledew, W. M. (2002). Influence of medium buffering capacity on inhibition of Saccharomyces cerevisiae growth by acetic and lactic acids. Appl. Environ. Microbiol. 68, 1616-1623.

Conflict of Interest Statement: The authors declare that the research was conducted in the absence of any commercial or financial relationships that could be construed as a potential conflict of interest.

Received: 08 May 2012; accepted: 02 September 2012; published online: 21 September 2012.

Citation: Kitanovic A, Bonowski F, Heigwer F, RuoffP, Kitanovic I, Ungewiss $C$ and Wölfl S (2012) Acetic acid treatment in $S$. cerevisiae creates significant energy deficiency and nutrient starvation that is dependent on the activity of the mitochondrial transcriptional complex Hap2-3-4-5. Front. Oncol. 2:118. doi: 10.3389/fonc.2012.00118

This article was submitted to Frontiers in Molecular and Cellular Oncology, a specialty of Frontiers in Oncology. Copyright (C) 2012 Kitanovic, Bonowski, Heigwer, Ruoff, Kitanovic, Ungewiss and Wölfl. This is an open-access article distributed under the terms of the Creative Commons Attribution License, which permits use, distribution and reproduction in other forums, provided the original authors and source are credited and subject to any copyright notices concerning any third-party graphics etc. 